\title{
Reproducing Failure Mode and Life Prediction of Expansion Joint Using Field Data
}

\author{
Jung Soo Oh, Sueng Hyun Cho, Sung Jae Won, Dae Kyung Kang, Bong Soo Lee, Joong Sik Heo \\ Machine \& Mensuration Division, Korea Testing Certification, Gun-po city, South Korea \\ Email address: \\ ojs82@ktc.re.kr(J.S. Oh), shcho@ktc.re.kr(S.H.Cho),kangdk@ktc.re.kr(D.K.Kang), bs7624@ktc.re.kr(B.S. Lee), \\ jsheo@ktc.re.kr(J.S. Heo)
}

\section{To cite this article:}

Jung Soo Oh, Sueng Hyun Cho, Sung Jae Won, Dae Kyung Kang, Bong Soo Lee, Joong Sik Heo. Reproducing Failure Mode and Life Prediction of Expansion Joint Using Field Data. International Journal of Mechanical Engineering and Applications.

Vol. 6, No. 1, 2018, pp. 13-17. doi: 10.11648/j.ijmea.20180601.12

Received: February 12, 2018; Accepted: April 16, 2018; Published: April 27, 2018

\begin{abstract}
In this study, among plant equipment, valve and piping fitting which is vulnerable to waterhammer was selected for diagnosis. Impulsive vibration by waterhammer was measured and applied to HIL simulator as operation data using HILS method for reproducing failure mode and life prediction of them. For effective measuring vibration, accelerometer was adapted for in the poor surroundings. Measurement results shows max. peak-to-peak vibration displacement was $21.40 \mathrm{~mm}$ caused by waterhammer on the valve etc., which could affect structure stability of plant equipment. After that, using the acquired data, the vibration durability of the expansion joint was tested. Meanwhile, in the case of vibration durability, internal pressure in the expansion joint was proposed as main stress factor of durability life, life prediction model was induced by curve fitting along with the datum at each pressure and verified. Thus, a further study will develop mixed life prediction model which will contain another stress factor such as temperature.
\end{abstract}

Keywords: Expansion Joint, Failure Mode Reproducing, HILS, Life Prediction, Plant Equipment, Waterhammer

\section{Introduction}

In the case of safety diagnosis of plant equipment at present, collecting data in the field are analyzed and stored as DB for maintenance and replacement.

Also, most commercial plant equipment products is examined and tested by domestic and international test standards such as KS, ISO, ANSI/ASME. [1-3]

Nevertheless, It is difficult to predict the actual life of product since product performance depends on actual operating environment and conditions. Especially, under a excessive condition such as waterhammer, the product is vulnerable to breakage easily. So, it is not possible to predict the actual life exactly.

Recently, using HILS (hardware-in-the-loop simulation) method has been adopted for improving reliability and has been extended throughout all industries because HILS is very powerful reliability method which is reflecting actual operation condition. But, safety assessment of plant field has not reported yet. $[4,5]$

HILS is one of the techniques for life assessment as applying to repeating the specific conditions on a object until it fails or failure. Therefore, attempt to introduce HILS in the safety assessment of plant equipment would be effective.

For repeated application of a certain condition, some of operating datum were measured, which of them was applied to operating data of HIL simulator.

Also, in the case of reproducing failure, Among the plant equipment, the expansion joint was selected and tested.

Reproducing failure mode was carried out according to each conditions and then, using the results of each failure cycle, life prediction model was induced and verified in this study.

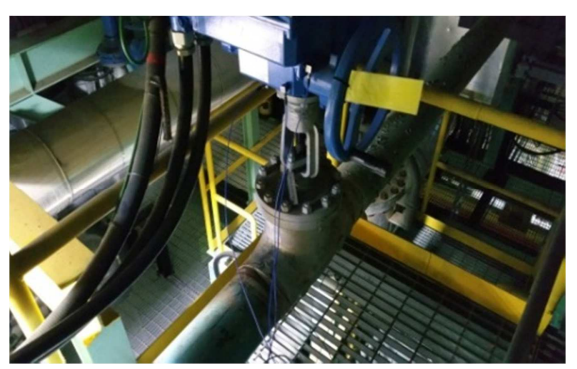

(a) High temperature and high vibration 


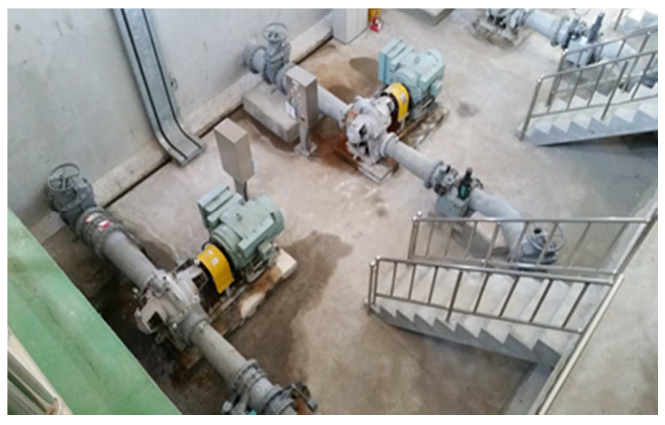

(b) high humidity and low temperature

Figure 1. Examples of diagnosis environment.

\section{Selection of Environment and Object Diagnosis}

\subsection{Selecting Sensor for Diagnosis}

Waterhammer can damage to pump, valve and expansion joint by feeding and stopping transfer fluid abruptly in pipeline. [6]

In order to reduce excessive impact, a safety equipment such as air-chamber has been adopted these days. But, It is not easy to applied for aged plant environment considering installation space and high cost. Therefore, lots equipment are need to repaired and replaced in many places up until now. Accordingly, valve etc. with high probability of being exposed to waterhammer were selected in this study.

Some studies report the causes of transient response and damage in piping systems on using accelerometer when measuring vibration. [7-9]

In the case of application of non-contact displacement sensor, which has narrow measurement range and need additional jig for installation despite of high resolution. Also removal coating layer and surfacing procedure are required to surface of piping and equipment.

Laser measurement for displacement has high resolution with sub-micron level but, is vulnerable to temperature, humidity, wind and base excitation. So that is not suitable to unstable environment in Figure 1 [10]

Therefore, In this study, accelerometer was selected for vibration considering comprehensive conditions and vibration displacement was induced by integrated initial value twice.

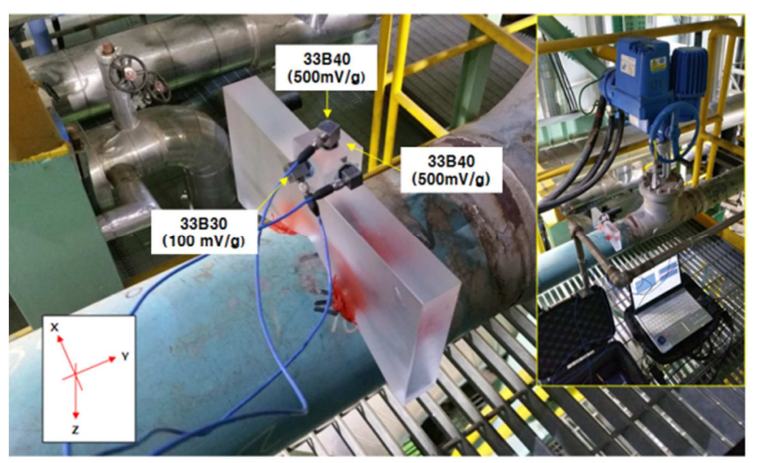

Figure 2. Setup for waterhammer in the power plant pipeline.
Table 1. Specification of accelerometers.

\begin{tabular}{lll}
\hline Specification & 333B30 & 333B40 \\
\hline Sensitivity $(\mathrm{mV} / \mathrm{g})$ & 100 & 500 \\
Measurement Range $(\mathrm{g})$ & \pm 50 & \pm 10 \\
Temperature Range $\left({ }^{\circ} \mathrm{C}\right)$ & $-18 \sim 66$ & \\
Frequency Range $(\mathrm{Hz})$ & $0.5 \sim 3,000$ & \\
Resonant Frequency $(\mathrm{Hz})$ & $>3,000$ & \\
Non-Linearity $(\%)$ & $<1$ & \\
Sensing Element & Ceramic & \\
Note & $\mathrm{g}=\mathrm{m} / \mathrm{s}^{2}$ & \\
\hline
\end{tabular}

\subsection{Data Measurement}

Figure 2 indicates the setup for measuring vibration on the valve by waterhammer. Diagnosis object is 6 inch glove valve which is made of A216-WCB. Working fluid is hightemperature water, design pressure is $50 \mathrm{~kg}_{\mathrm{f}} / \mathrm{cm}^{2}$, design temperature is up to $250^{\circ} \mathrm{C}$. And this valve is connected and supported to pipe by welding.

Major failure mode became known as crack on valve body and disk breakage of valve

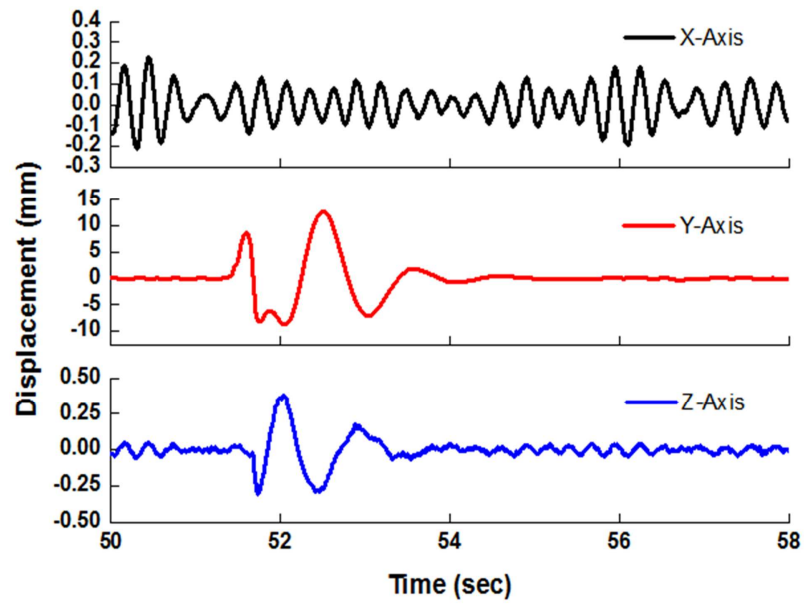

(a) Displacements after 1st waterhammer

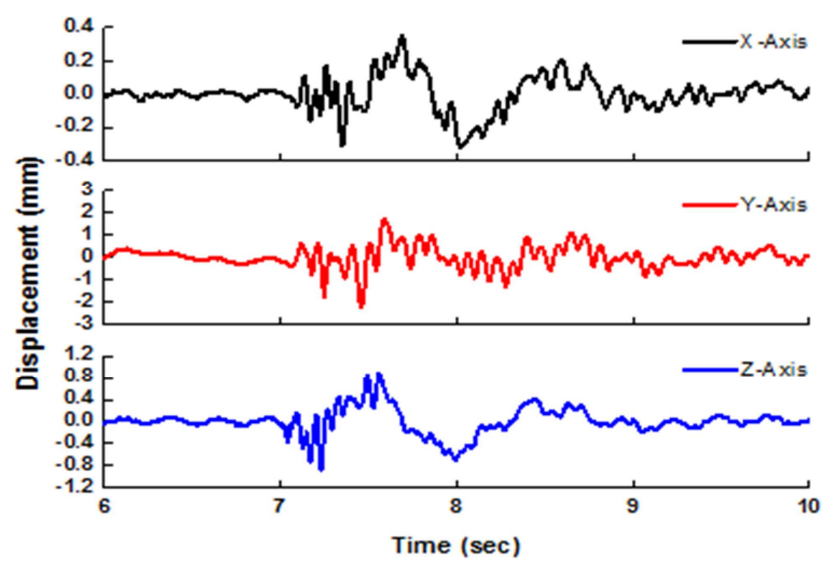

(b) Displacements after $2^{\text {nd }}$ waterhamme

Figure 3. Displacements after waterhammer

Before measuring, surface temperature of valve body was $84 \sim 90^{\circ} \mathrm{C}$. So, acrylic block was attached for setting accelerometer to minimize thermal effect. Also, to avoid 
amplification of measured value, placing at a position from surface of pipe with $30 \mathrm{~mm}$ above. At that time, temperature of sensing part(acrylic block ) was $40 \sim 42^{\circ} \mathrm{C}$ and lie at operating range of Table. 1 and accelerometers were set along with 3 -axis direction.

Figure 3 is the edited results which are pre and post section during 60- sec measurement period.

Displacements of Figure 3 (a) is the results $1^{\text {st }}$ waterhammer which are measured about $51-\mathrm{sec}$ from Initial measurement point. and displacements of Figure 3 (b) is the results $2^{\text {nd }}$ waterhammer are measured about $7-\mathrm{sec}$ from re-measurement point.

In the results of Figure 3 (a), there are two times impacts in the direction of the Y-axis. Max. peak to peak (p-p) of displacement was $21.40 \mathrm{~mm}$ level, $\mathrm{p}$-p value of displacement was $0.68 \mathrm{~mm}$ level in the direction of the Z-axis. Also, p-p value of displacement was $3.90 \mathrm{~mm}$ level in the direction of the Y-axis and $1.7 \mathrm{~mm}$ level in the direction of the Z-axis in the Figure 3 (b)

Considering results of each direction, displacements of $X$ and Z-axis had smaller than Y-axis. This would be affected by connection structure with $\mathrm{X}$ and $\mathrm{Z}$-axis direction

\subsection{HIL Simulator}

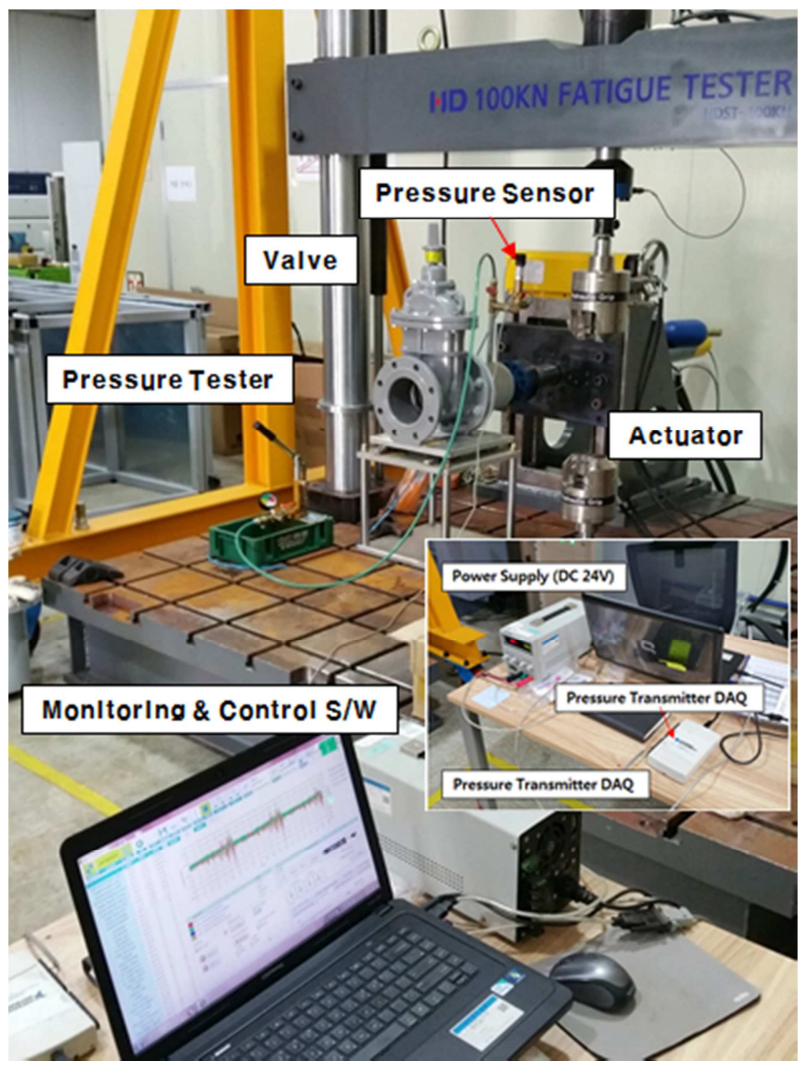

Figure 4. HIL simulator for vibration reproducing.

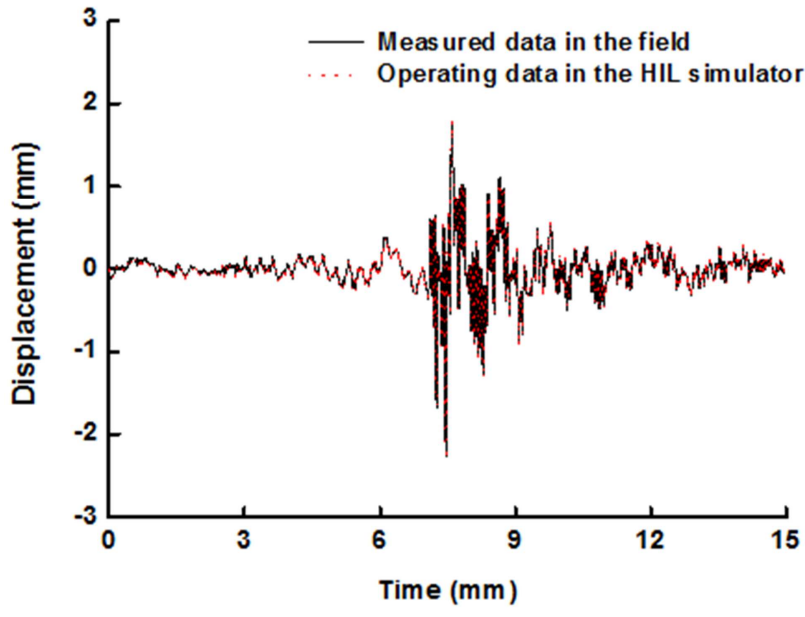

Figure 5. Comparison between measured data and operating data.

Figure 4 shows HIL simulator for vibration reproducing. This simulator can carry out multi-axis and has displacement \& load control as well. Also, software for HIL simulator can operate random wave and monitor number of reproducing.

Abnormal signal from a sensor(e.g. pressure) which was attached to can be detected for failure mode.

For verification of the vibration reproduction, Y-axis data of Figure 3 (b) was applied as operation data and compared in the Figure 5. At that time, following error was $0.01 \mathrm{~mm}$ level. Hence, it is possible to reproduce displacement with mm level.

\section{Failure Mode Reproduction}

\subsection{Test Setup}

In this study, vibration durability tests were constructed as shown in Figure 6 to reproduce failure mode of expansion joint using measured data at section 2. The specimen is bellows type expansion joint (150A).

Expansion joint usually is used for preparation such as excessive thermal deformation, shock by waterhmmer in the plant system widely.

Design pressure of expansion joint is $20 \mathrm{~kg}_{\mathrm{f}} / \mathrm{cm}^{2}$, expansion length is $\pm 15 \mathrm{~mm}$. and material of flange and bellows is SS400 and STS 304 respectively. Also expansion joint is consist of bellows and sleeve with $0.6 \mathrm{t}$ by welding

Major failure mode of expansion joint are leakage by crack, deformation and breakage of connection to pipe by shock.

Test setup is consist of hydraulic actuator system (Max. $100 \mathrm{kN}$ ) and software for control and monitoring. Expansion joint was connected to actuator, water pressure tester is set for supplying water and adjusting pressure and air-chamber for maintaining initial setting pressure. Lastly, pressure transmitter was attached for monitoring real-time pressure state. 


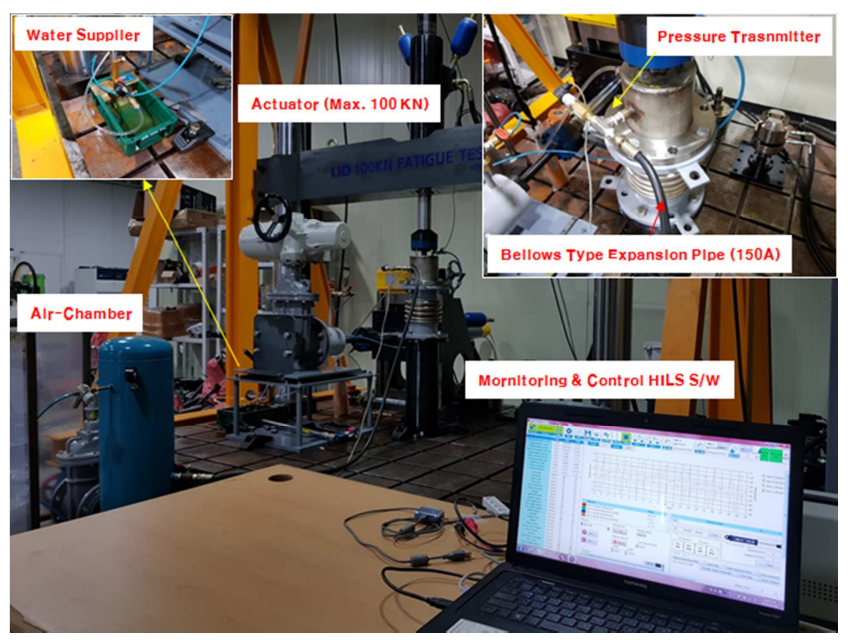

Figure 6. Set-up for durability test of expansion joint for failure reproducing.

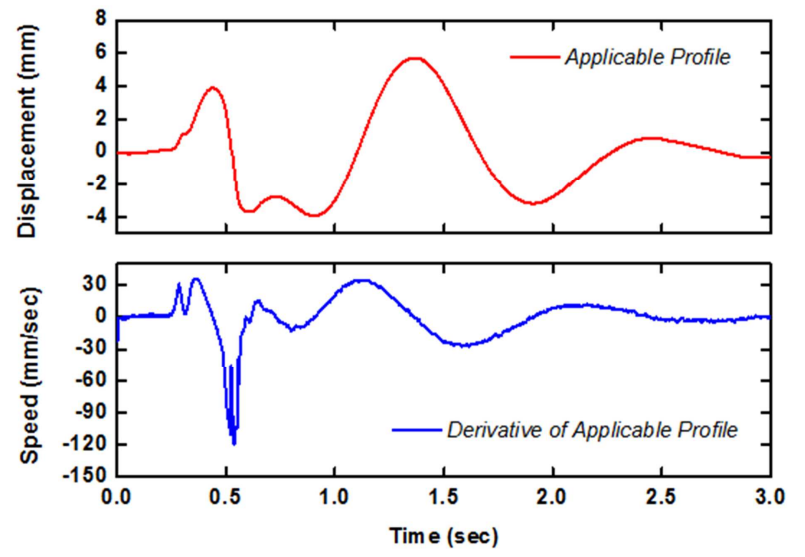

Figure 7. Operating data applied to HIL Simulator for vibration reproducing.

\subsection{Test Scheme}

The main causes of failure of the expansion joint are sudden internal pressure change, thermal change of working fluid and breakage by external impact. In this study, external impulse was applied for vibration durability of expansion at first.

In addition, this study suppose that internal pressure of expansion joint is the major stress factor in durability life.

Test conditions is shown in Table 2., Test was finished when leakage was occurred during the test.

Table 2. Test condition according to internal pressure of expansion joint.

\begin{tabular}{lll}
\hline Case & Pressure $\left(\mathrm{kg}_{\mathrm{f}} / \mathbf{c m}^{\mathbf{2}}\right)$ & Q'ty of Specimen \\
\hline I & 10 & 3 \\
II & 11 & 3 \\
III & 13 & 3 \\
\hline
\end{tabular}

\subsection{Test Results}

Results at each internal pressure are presented in Table 3. In the case of $10 \mathrm{~kg}_{\mathrm{f}} / \mathrm{cm}^{2}$, average life up to failure was 2,700 cycle. Also, In the case of $11 \mathrm{~kg}_{\mathrm{f}} / \mathrm{cm}^{2}$ and $13 \mathrm{~kg}_{\mathrm{f}} / \mathrm{cm}^{2}$, average life was 1,800 cycle and 1,000 cycle individually.

On the other hand, the life deviation was inclined to increased as internal pressure was lower. This phenomenon was estimated that deformation and expansion of bellows part was proceeded slowly at lower pressure.

Failure mode during the test was shown in Figure 8

Table 3. Test results for each condition (cycle).

\begin{tabular}{llll}
\hline Pressure $\left(\mathbf{k g}_{\mathrm{f}} / \mathbf{c m}^{2}\right)$ & Specimen & Life (cycle) & $\begin{array}{l}\text { Average Life } \\
\text { (cycle) }\end{array}$ \\
\hline \multirow{3}{*}{10} & $\# 1$ & 2,403 & \\
& $\# 2$ & 2,589 & 2,733 \\
& $\# 3$ & 3,208 & \\
11 & $\# 1$ & 2,025 & \\
& $\# 2$ & 1,890 & 1,814 \\
& $\# 3$ & 1,528 & \\
13 & $\# 1$ & 1,138 & \\
& $\# 2$ & 1,257 & 1,073 \\
\hline
\end{tabular}

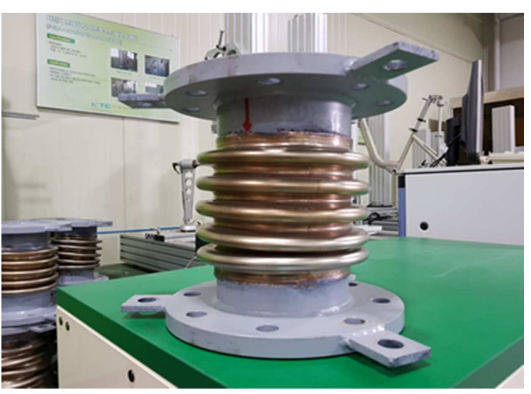

(a) Deformation

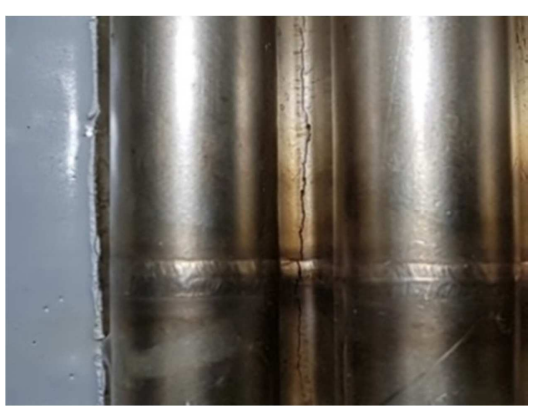

(b) Crack on surface of bellows part

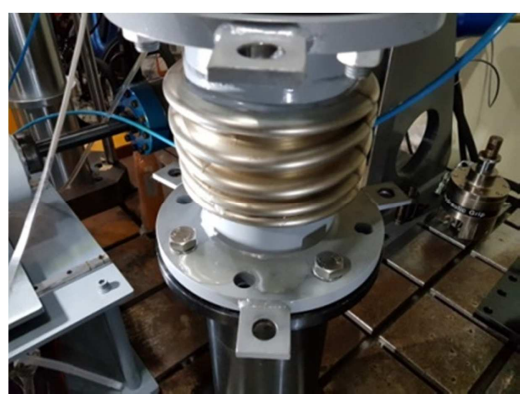

(c) Leakage during durability test

Figure 8. Failure mode.

\section{Development of life Prediction Model}

\subsection{Life Prediction Model}

Assuming that life of the expansion joint follow inverse power model which is suitable to mechanical components. 
Then, life model equation is proposed as (1) below.

$$
L=A_{1} e^{-\left(\frac{P_{\text {in }}}{S}\right)}+C
$$

Where,

$L=$ Prediction life (cycle)

$A_{1}=$ Constant of inverse power model

$P_{i n}=$ Stress factor (inner pressure)

$S=$ Stress index

$C=$ Constant

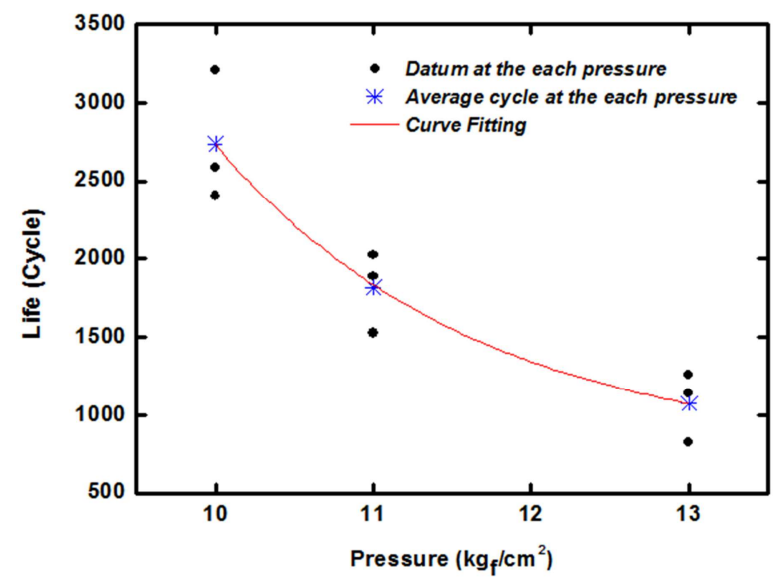

Figure 9. Curve fitting for datum at each pressure.

In order to derive coefficients of equation, the test results at each pressure were illustrated as Figure 10 and then, a curve was inserted along with the results for finding tendency of datum. After that, the each coefficient was induced that $A_{1}$, $\mathrm{S}$ and $\mathrm{C}$ was $845,907.9,1.651$ and 750.8 at each.

\subsection{Verification of Life Prediction Model}

For verification of life prediction model in this study, vibration durability tests at $7 \mathrm{~kg}_{\mathrm{f}} / \mathrm{cm}^{2}$ was performed as shown in Table 4.

It turned out that average life was 12,400 cycle, It was close to estimated value, 12,946 cycle by life prediction model within deviation range comparatively.

Table 4. Test results at $7 \mathrm{~kg} / \mathrm{cm}^{2}$.

\begin{tabular}{llll}
\hline Pressure $\left(\mathrm{kg}_{\mathrm{f}} / \mathbf{c m}^{2}\right)$ & Specimen & Life (cycle) & $\begin{array}{l}\text { Average Life } \\
\text { (cycle) }\end{array}$ \\
\hline \multirow{3}{*}{7} & $\# 1$ & 15,128 & \\
& $\# 2$ & 11,229 & 12,420 \\
& $\# 2$ & 10,904 & \\
\hline
\end{tabular}

\section{Conclusion}

In this study, plant equipment which is vulnerable to waterhammer was made diagnosis and predicted life of expansion joint by reproducing failure mode.

Using an accelerometer that is relatively easy to install, displacement vibration by waterhammer was measured and applied to vibration durability tests.

Also, internal pressure of expansion joint is the major factor in durability life was assumed, verified and life prediction model was induced in this study.

However, the life prediction model in this study has limitation on specific surroundings and operating condition. Hereby, in addition to pressure, temperature will be considered as stress factor, mixed life prediction model will be developed in the future.

\section{Acknowledgments}

This research was supported by a grant (No. 18IFIP-B089065-05 \& No. 16CTAP-C117188-01) from Technology Advancement Research Program funded by Ministry of Land, Infrastructure and Transport of Korean government.

\section{References}

[1] "KS B 4500: Expansion Joints", Korea Standard Association, 2016.

[2] "ISO 15348(en): Pipework-Metal bellows expansion joints", International Organization for Standardization, 2002.

[3] "ASME B31.3: Processing Piping", The American Society of Mechanical Engineers", 2016.

[4] S. Olma, A. Kohlstedt, P. Traphoner, K. P. Jaker, A. Trachtler, "Substructuring and Control Strategies for Hardware-in-the-Loop Simulations of Multiaxial Suspension Test Rigs", the Journal of International Federation of Automation Control, Vol. 49, Issue 21, pp. 141-148, 2016R. Nicole, "Title of paper with only first word capitalized," J. Name Stand. Abbrev.

[5] K. Y. Jeong, R. C. Kang, H. C. Lee, "Prediction of Iron Loss Resistance by Using HILS System", The Korean Society Of Automotive Engineers, Transaction of the Korean Society of Automotive Engineers, Vol. 23, No. 1, pp25-33, 2015M. Young, The Technical Writer's Handbook. Mill Valley, CA: University Science, 198.

[6] J. H. Lee, H. H. Lee, B. H. Kyoung, J. W. Woo, K. H. Lee, " A Study of Water-Hammer Control with Statuette-Piping", The Korean Society for Noise and Vibration Engineering, Annual Spring Conference, pp. 674-678, 2007.

[7] J. S. Suh, "A Study on the Measurement of the Pipeline Displacement Using Accelerometers", The Korean Society for Noise and Vibration Engineering, Vol. 24, No. 6, pp. 476-482, 2016.

[8] Y. H. Kim, "Examination on High Vibration and Branch Vent Pipe's Failure of Complex Piping System Suppling Condensate-water in Power Site", The Korean Society for Noise and Vibration Engineering, Annual Autumn Conference, pp. 380 384. 2010 .

[9] Y. C. Bae, Y. S. Lee and Y. H. Kim, "Countermeasure on High Vibration of Branch Pipe with Pressure Pulsation Transmitted from Main Steam Header, Transactions", The Korean Society for Noise and Vibration Engineering", Vol. 15, No. 8, pp. $988 \sim 995,2005$.

[10] Hewlett Packard Co., "Laser Measurement System User's Guide, Manual Part No. 00528-90010," 1984. 